\title{
An Actin-associated Protein Present in the Microtubule Organizing Center and the Growth Cones of PC-12 Cells
}

\author{
E. L. Bearer \\ Department of Biochemistry and Biophysics, University of California, San Francisco, California 94143-0448
}

\begin{abstract}
The pathfinding ability of the growth cone depends upon the integrity of a dynamic actin filament network. However, although a number of actin-binding proteins have been found in growth cones, it is not known how these proteins come to be concentrated there or how they might interact to produce these important actin filaments. In this report, an actinassociated protein recognized by the monoclonal antibody 2E4 is demonstrated to be present in PC-12 cells. In undifferentiated cells, this protein is present in an apparently inactive state in a perinuclear location that corresponds to that of the microtubule organizing center and not of the Golgi apparatus. Conversely, after NGF-induced differentiation, the antigen is found enriched in the neurite and growth cone and disappears from the perinuclear position. This disappearance is directly proportional to the length of the neurite. The antigen-antibody complex binds the ends of actin filaments in vitro in an ATP-sensitive manner, and the antibody stains the outermost edge of the actin filament ruffle in the leading edge of migrating fibroblasts. Hence, it is possibly involved in the membrane-associated polymerization of actin filaments such as that observed in growth cones.
\end{abstract}

The growth cone of the neuron is responsible for guiding the neurite along the path that will determine its neuronal connections. An intact actin filament system is crucial for this guidance (Marsh and Letourneau, 1984), probably in part because of its structural contribution, but also because of its role in regulating the distribution of transmembrane receptors (Sheetz et al., 1990). The actin filament-rich network in the anteriormost lamellipodia of the growth cone resembles the leading edge of migrating cells. The similarities include the dynamic ruffling of the membranes (Trinkaus, 1984), the apparent polymerization of actin filaments on the membrane surface (Wang, 1985; Forscher and Smith, 1988), and the propulsive nature of the two processes. Thus, proteins regulating actin dynamics in the leading edge may also play similar roles in the neuronal growth cone.

The rat pheochromocytoma cell line, PC- 12 cells, have proven to be a useful system in which to study growth cone formation

Received Mar. 26, 1991; revised Sept. 27, 1991; accepted Oct. 1, 1991.

I thank Ken Sawin and Tim Mitchison for isolated centrosomes, J. Pate Skene for isolated neonatal rat brain growth cones, and Bruce Alberts for his generous support. I am also indebted to Lou Reichardt, Tim Mitchison, and Victoria Allan for helpful discussions. This work was supported by California Division American Cancer Society Fellowship S-44-89, the Frederick Bang Award from the Marine Biological Laboratory, Woods Hole, MA, and National Institutes of Health Grant GM23928.

Correspondence should be addressed to E. L. Bearer, Division of Biology and Medicine, Box G, Brown University, Providence, RI 02912.

Copyright (C) 1992 Society for Neuroscience $0270-6474 / 92 / 120750-12 \$ 05.00 / 0$ and neurite outgrowth (Greene and Tischler, 1976). In the unstimulated state, these cells are round, projecting a few filopods but no neurites or growth cone-like structures. Upon stimulation with NGF, they project neurites tipped by small growth cones. Both the cell body and these growth cones respond to NGF initially with membrane ruffling, an event that involves actin polymerization (Connolly et al., 1984). Although purified actin can polymerize in vitro under appropriate salt and nucleotide conditions, it is generally believed that the site-specific polymerization of actin on a membrane surface, such as that observed in PC-12 cells upon NGF stimulation or in Aplysia neuronal growth cones (Forscher and Smith, 1988), involves some sort of nucleator residing on the cytoplasmic surface of the membrane and influencing the site of actin polymerization, its orientation with respect to the membrane, and the rate of barbed end elongation (Tilney et al., 1981; Pollard and Cooper, 1986). Although several actin-associated proteins have been identified in growth cones, including myosin (Bridgeman and Dailey, 1989), fodrin, and $\alpha$-actinin (Gordon-Weeks, 1987), their contribution to actin dynamics fails to explain the behavior of actin observed in growth cones. Therefore, some additional unidentified factors that regulate the formation of actin filaments must be present at the leading edge of the growth cone. However, it remains a puzzle how any of these actin-binding proteins come to be enriched in the growth cone, since no protein synthesis apparently happens there. The current idea is that such proteins are transported out the neurite from the cell body by some active transport process (reviewed in Vallee and Bloom, 1991). Actin itself appears to arrive via a slow transport process that may involve incorporation into actin filaments along the length of the neurite during transport (Okabe and Hirokawa, 1990).

The monoclonal antibody (MAb) 2E4 was raised against human blood platelet proteins eluting with ATP from filamentous actin affinity columns (E. L. Bearer, unpublished observations). It recognizes a $43 \mathrm{kDa}$ protein by immunoblots that is enriched in the leading edge of migrating chick embryo fibroblasts. The purpose of this study was to investigate whether the MAb 2E4 antigen was present in growth cones and, if so, to study its distribution before and after neurite outgrowth. Since PC-12 cells can be stimulated by NGF to differentiate and produce growth cones, they are a suitable system in which to pose the following questions: is the expression of the MAb 2E4 antigen induced by NGF or is it present in the undifferentiated cell, and if present prior to induction, where is it located? Furthermore, does the ncuronal protcin also bind the ends of filaments in the same way as the antigen extracted from human platelets or chick fibroblasts? Finally, after NGF stimulation, is the antigen found in growth cones? It was believed that the presence and location 
of the antigen prior to NGF stimulation would provide clues concerning the mechanism by which it becomes enriched in the growth cone and, by analogy, to the leading edge of fibroblasts and other motile cells.

\section{Materials and Methods}

Cells. PC-12 cells were obtained from the Cell Culture Facility [University of California, San Francisco (UCSF)] and grown from the 10th to 20th passages in DME H21 (Cell Culture Facility, UCSF) supplemented with $5 \%$ fetal calf serum, $10 \%$ horse serum, and antibiotics. Cells were passaged by squirting off the bottom of the plate with fresh media. Some cultures were stimulated with nerve growth factor (mouse submaxillary gland, S7 type, Calbiochem, La Jolla, CA) at a final concentration of $25-50 \mathrm{ng} / \mathrm{ml}$ of culture media. Cells were stimulated for $3 \mathrm{~d}$ to 1 week, with fresh NGF added every $2 \mathrm{~d}$. For microscopy, cells were grown on either polylysine-coated (unstimulated and stimulated) or Matrigel (Collaborative Research, La Jolla, CA)-coated coverslips (stimulated). Neurite outgrowth was more pronounced and growth cones adhered better during staining procedures when cells were grown on Matrigel. All other parameters appeared unchanged. In one experiment, cells grown on coverslips were treated with lysis buffer containing $0.5 \%$ Triton X-100 for 1 min before fixation.

Extractions. For ATP extracts, cells were allowed to grow just short of confluence in $100 \mathrm{~mm}$ plastic culture dishes and then washed three times with serum-free media. Whole cells were either solubilized directly in boiling gel sample buffer after this step, or prepared for ATP extraction as follows: after removing the media, $0.5 \mathrm{ml}$ of lysis buffer $(50 \mathrm{mM} \mathrm{KCl}$,

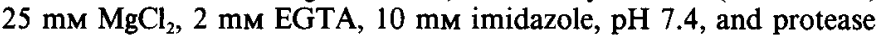
inhibitors: $1 \mathrm{~mm}$ phenylmethylsulfonyl fluoride, and $10 \mu \mathrm{g} / \mathrm{ml}$ leupeptine, pepstatin, aprotinin, and benzamidine) was added to the dish, and cells were scraped off the culture plate with a rubberized spatula. Cells were lysed by adding Triton X-100 to a final concentration of $0.5 \%$ to $1.5 \mathrm{ml}$ of cell suspension from three culture dishes. The lysate was centrifuged for $15 \mathrm{~min}$ at $100 \%$ speed in a microfuge $(16,000 \times \mathrm{g})$ and then washed in three changes of wash buffer [ $100 \mathrm{~mm} \mathrm{KCl}, 2$ mM EGTA, $10 \mathrm{~mm}$ imidazole, $\mathrm{pH} 7.4,0.2 \mathrm{~mm}$ dithiothreitol (DTT), and protease inhibitors as before]. The final pellet was extracted for $15 \mathrm{~min}$ on ice with $300 \mu \mathrm{l}$ of $5 \mathrm{~mm} \mathrm{ATP}$ and $10 \mathrm{~mm} \mathrm{MgCl}_{2}$ in the same buffer, and the nonextracted sediment was pelleted in the microfuge as before. The resulting supernatant, the ATP extract, was used for immunoblots or in the actin-binding assay. Proteins were separated by standard Laemmli SDS-polyacrylamide gel electrophoresis and either stained with Coomassie blue or transferred to nitrocellulose at $50 \mathrm{~mA}$ overnight followed by $300 \mathrm{~mA}$ for $2 \mathrm{hr}$ in $25 \%$ methanol, $0.1 \% \mathrm{SDS}$, and $16 \mathrm{gm} /$ liter glycine. After transfer, the blot was blocked in $5 \%$ bovine serum albumin, 0.1 $\mathrm{M}$ Tris- $\mathrm{HCl}$ (pH 7.5), and $0.15 \mathrm{M} \mathrm{NaCl}$ for $1 \mathrm{hr}$, and then stained with a 1:1000 dilution of ascites fluid made with the hybridoma 2E4 for 1$3 \mathrm{hr}$ in the same buffer plus $0.05 \%$ Tween-20 (Bio-Rad). Ascites from several different mice were used with identical results. After three washes with the same buffer for $15 \mathrm{~min}$ each, the blot was stained with a 1: 5000 dilution of alkaline phosphatase-conjugated goat anti-mouse IgM (Boehringer-Mannheim) for $1 \mathrm{hr}$ in the same buffer.

Centrosomes were a gift from Ken Sawin and Tim Mitchison (University of California, San Francisco), and were isolated according to published protocols that follow microtubule nucleating activity (Mitchison and Kirschner, 1986). Growth cones were isolated from brains of 5-d-old rats according to published protocols (Skene and Virag, 1989).

Actin flament binding assay. Actin filament binding assays were performed as previously described (Bearer, 1991, unpublished observations). This is a modification of the myosin motility assay described in Kron et al. (1991). Coverslips coated with $0.1 \%$ nitrocellulose in amylacetate were allowed to air dry and then inverted onto a perfusion chamber made from two shards of no. 1 glass coverslips sealed with Apiezon vacuum grease (EM Sciences) on a glass microscope slide. The chamber was first perfused with $50 \mu \mathrm{l}$ of a 1:200 dilution of MAb 2E4 ascites diluted in assay buffer ( $10 \mathrm{~mm}$ imidazole, pH 7.4, $20 \mathrm{~mm} \mathrm{KCl}, 1 \mathrm{~mm}$ EGTA, $4 \mathrm{mM} \mathrm{MgCl}$, and $0.5 \mathrm{~mm}$ DTT). After $5 \mathrm{~min}$, the perfusion chamber was washed and blocked with four changes of assay buffer plus $0.1 \%$ bovine serum albumin, and then $50 \mu$ of ATP extract were perfused into the chamber and allowed to incubate for 5-10 min, and the chamber was washed as before. Finally, actin filaments, purified from rabbit skeletal muscle and labeled with rhodamine-phalloidin (Molecular Probes, Eugene, OR), were perfused into the chamber at a concentration of $1-2 \mu \mathrm{g} / \mathrm{ml}$. Alternatively, coverslips were incubated with blocking buffer alone, or with extract without being initially blocked. As a final control, coverslips coated with antibody were blocked and exposed to actin filaments without extract. After incubation with actin filaments, the perfusion chamber is washed with assay buffer containing an oxygen radical scavenging system composed of glucose oxidase $(0.1$ $\mathrm{mg} / \mathrm{ml})$, catalase $(0.018 \mathrm{mg} / \mathrm{ml})$, and glucose $(30 \mathrm{mg} / \mathrm{ml})$. A blue ink mark was made at the side of the surface of the coverslip on which the filaments were expected to adhere so that the focal plane could be identified. This was particularly important in control coverslips when no filaments bound to the glass, in which case it would have been impossible to be certain that the correct focal plane had been found without the ink mark. Preparations were observed on a Nikon fluorescence photomicroscope equipped with a $100 \mathrm{~W}$ mcrcury lamp and were photographed with $20 \mathrm{sec}$ exposures on Kodak TMax ASA 400 film.

Immunofluorescence. Cells grown on poly-L-lysine-coated glass coverslips (Miles Scientific) were fixed in 4\% paraformaldehyde with $0.25 \%$ Triton X-100 in Small's cytoskeletal buffer $(137 \mathrm{~mm} \mathrm{NaCl}, 5 \mathrm{~mm} \mathrm{KCl}$, $1 \mathrm{mM} \mathrm{Na}_{2} \mathrm{HPO}_{4} \cdot 2 \mathrm{H}_{2} \mathrm{O}, 0.4 \mathrm{~mm} \mathrm{KH}_{2} \mathrm{PO}_{4}, 5.5 \mathrm{~mm}$ glucose, $4 \mathrm{~mm} \mathrm{NaHCO}$, $2 \mathrm{~mm} \mathrm{MgCl}_{2}, 2$ mM EGTA, $10 \mathrm{~mm}$ MES, pH 6.1) (Rinnerthaler et al., 1988). Staining of live cells was performed by incubating coverslips of cultured cells with $1 \mathrm{mg} / \mathrm{ml} \mathrm{C}_{6}$-NBD-ceramide (Molecular Probes) in cell culture medium for $15 \mathrm{~min}$, followed by extensive washes in culture media, and then mounting in a perfusion chamber for observation live in the fluorescence microscope (Pagano et al., 1989). To depolymerize microtubules, cells were treated with $10 \mu \mathrm{g} / \mathrm{ml}$ colcemid (Sigma Chemical Co.) in cell culture medium for $15 \mathrm{~min}$ at $37^{\circ} \mathrm{C}$ prior to fixation. For all antibody staining, the fixed cells were washed in phosphatebuffered saline (PBS), blocked for 10 min with $0.1 \%$ Triton X-100 and $1 \%$ bovine serum albumin in PBS, incubated with primary antibody [MAb 2E4 at 1:1000, polyclonal anti-tubulin antibody (Collaborative Research) at 1:100, and a polyclonal anti-rat Golgi antibody (Brian Burke, Edinburgh University, Scotland) at 1:100] for $30 \mathrm{~min}$, washed with three to five changes of the same buffer, and stained with either rhodamine-labeled goat anti-mouse or fluorescein-labeled goat anti-rabbit secondary antibody (Cooper-Cappel) for $20-30 \mathrm{~min}$ in the same buffer. For staining with fluoresceinated wheat germ agglutinin $1: 400$ dilution; Vector Laboratories, San Mateo, CA), bovine serum albumin was omitted from the buffer, and the Triton was increased to $0.5 \%$. This permitted double staining with the other antibodies without a noticeable increase in nonspecific background or change in the pattern of labeling. Some preparations were double labeled with fluorcscin isothiocyanate (FITC)-phalloidin by adding the phalloidin (Sigma) to the secondary antibody solution at a 1:50 dilution. All preparations were additionally labeled with Hoechst 33258 (Sigma, $10 \mathrm{mg} / 100 \mathrm{ml}$ ethanol stock solution), which was added to the final wash at a dilution of $1: 100$ for a $10 \mathrm{~min}$ incubation. Fluorescent micrographs were photographed on a Nikon epifluorescent microscope using TMax ASA 400 (Kodak) black and white film, or Kodak Ektachrome Daylight for color double exposures.

Quantitation of the relationship between the presence of perinuclear staining and neurite outgrowth was performed by photographing randomly selected cells after NGF treatment that had been stained with $\mathrm{MAb} 2 \mathrm{E} 4$. The cells in the micrographs were scored for length of the longest neurite, and presence or absence of perinuclear staining. Three separate cultures were used for these counts.

\section{Results}

$M A b 2 E 4$ stains the leading edge of fibroblasts, a perinuclear structure in unstimulated $P C-12$ cells, and the neurite and growth cone of NGF-stimulated PC-12 cells

$\mathrm{MAb} 2 \mathrm{E} 4$ is a monoclonal antibody originally raised against a protein extracted from human blood platelets that eluted from F-actin with ATP. The antibody was selected because it stained the tips of platelet filopodia. It was further found to cross-react by immunofluorescence and Western blot with tissues from a wide variety of species, including chick embryo fibroblasts and the stereocilia of the chick cochlea, where it also stained the ends of actin filament-rich processes (Bearer, unpublished observations). Double staining of chick embryo fibroblasts with fluorescein phalloidin (Fig. 1A) and MAb 2E4 (Fig. 1B) revealed that the MAb 2E4 antigen is most prominent at the very pe- 

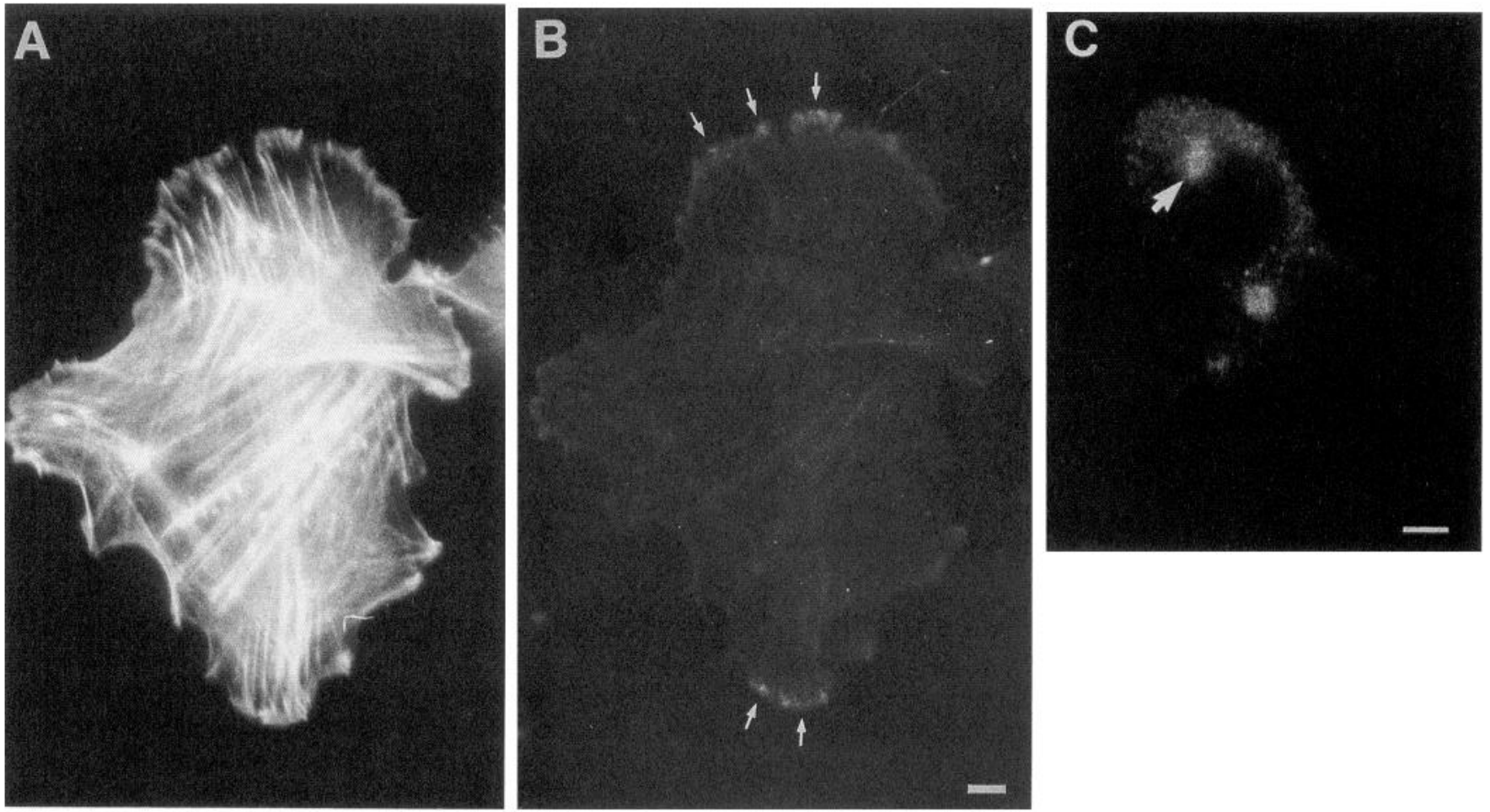

Figure 1. MAb 2E4 stains the leading edge of migrating cells and the cell body of unstimulated PC-12 cells. $A$ and $B$, Chick embryo fibroblast fixed and double labeled with FITC-phalloidin for actin filaments $(A)$ and MAb 2E4 $(B)$. Note the bright staining of MAb 2E4 at the tips of the actin ruffles (arrows in $B$ ). There is faint staining of stress fibers due to bleed-through of the very bright phalloidin staining in the fluorescein channel. $C$, Undifferentiated PC-12 cells stained with MAb 2E4. Note the bright perinuclear staining (arrow). Actin filaments are not prominent in these round cells. Scale bar, $5 \mu \mathrm{m}$.

riphery of the actin filament-rich leading edge. In apparently motile cells from subconfluent cultures, cytoplasmic staining was minimal. In unstimulated PC-12 cells, MAb 2E4 stained a perinuclear structure (Fig. $1 C$ ).

In response to $\mathrm{NGF}, \mathrm{PC}-12$ cells grown on Matrigel-coated coverslips sent out neurites with a fingerlike actin filament-rich growth cone at the distal end. In NGF-treated cultures, cells that had not responded to produce growth cones still had perinuclear staining, as did some cells with short processes (Fig. $2 A, B$, different focal planes of the same cell). Often the perinuclear staining (Fig. $2 A$ ) was not in the same plane as the neurites (Fig. $2 B$, same cell). In these cells, the cytoplasm also stained diffusely. This diffuse staining is more apparent in the micrograph focused on the neurites because of the longer exposure time needed to visualize the shorter neurites. In cells with longer processes, staining of the cell body was minimal compared to the neurite, which was brightly stained along its length, and the growth cone, which was even more strongly stained by the antibody (Fig. $2 C-E$ ). Even growth cones at the end of very long neurites were brightly stained (Fig. $2 E$ ), as were shorter neurites extending from the same cell body. Because the cells were grown on Matrigel, which does not always form a completely flat surface, parts of the cell are out of the focal plane. Because the antibody is an IgM, a very large isoform, and because the antigen is intracellular, the cells had to be permeabilized with nonionic detergent during fixation before any staining was appreciated. Several buffers were explored and the one that best preserved the cells as compared with nonperme- abilized cells was chosen for immunofluorescent studies. However, no buffer preserved the cells as well as fixation without detergent.

The staining was granular both along the process and in the growth cone. In branching growth cones, the staining was often not uniform, with brighter regions in the distalmost lamellae (Fig. 2D,E). The lack of staining in the cell body is unusual for cytoskeletal proteins-other growth cone-associated antigens such as ezrin and Gap-43 appear to be at least as concentrated in the cell body as in the growth cone (Goslin et al., 1989, 1990).

Double staining with MAb $2 \mathrm{E} 4$ (Fig. 3A) and phalloidin (Fig. $3 B$ ) revealed that actin filaments were present in the fixed growth cones in small tufts. In contrast to phalloidin staining, MAb 2E4 stained both the central part of the growth cone as well as the tufts and was much brighter along the neurite than phalloidin. At low magnification, the difference in intensity of antibody staining between the growth cone and the cell body was even more striking (Fig. $3 C$ ). Cells on a coverslip from the same culture, processed at the same time as the cells stained with MAb 2E4 but stained with a monoclonal anti-actin antibody instead, display the opposite staining distribution: bright cell bodies and less brightly stained neurites and growth cones (Fig. $3 D$ ). Because both MAb $2 \mathrm{E} 4$ and the anti-actin antibody are mouse IgM monoclonal antibodies, it was not possible to use them for double labeling indirect immunofluorescence. However, the fact that the anti-actin antibody is also an IgM provides strong evidence that the absence of staining by MAb 2E4 of the cell body is not an artifact of limited cell permeabilization. 

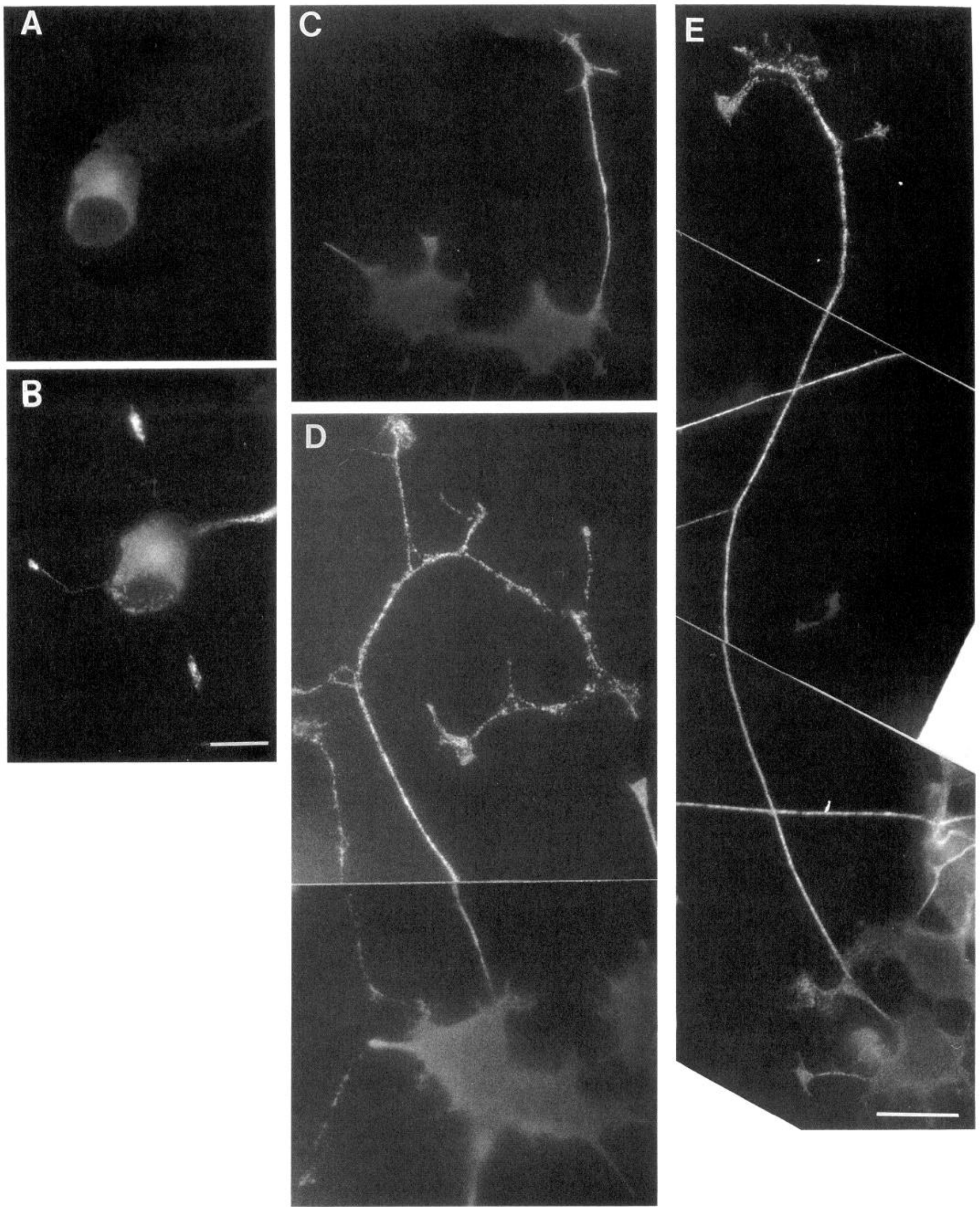

Figure 2. MAb 2E4 stains the neurite and growth cone after NGF-induced differentiation of PC-12 cells. $A$ and $B$, The same cell photographed at two different focal planes. In this cell, in the early stages of neurite extension, the perinuclear staining is still present $(A)$, while bright fluorescence also extends out the short processes ( $B$, the same cell at a different focal plane). $C-E$, Representative cells from the same culture grown on Matrigel and treated with NGF for $7 \mathrm{~d}$, fixed, and stained by indirect immunofluorescence with MAb 2E4. In any given culture, cells with different lengths of neurites are present as well as cells that remain undifferentiated. The cell body is only very weakly fluorescent, while the neurite and growth cones of all processes, both short and long, are brightly fluorescent. Scale bars: $A$ and $B, 10 \mu \mathrm{m} ; C-E, 20 \mu \mathrm{m}$. 

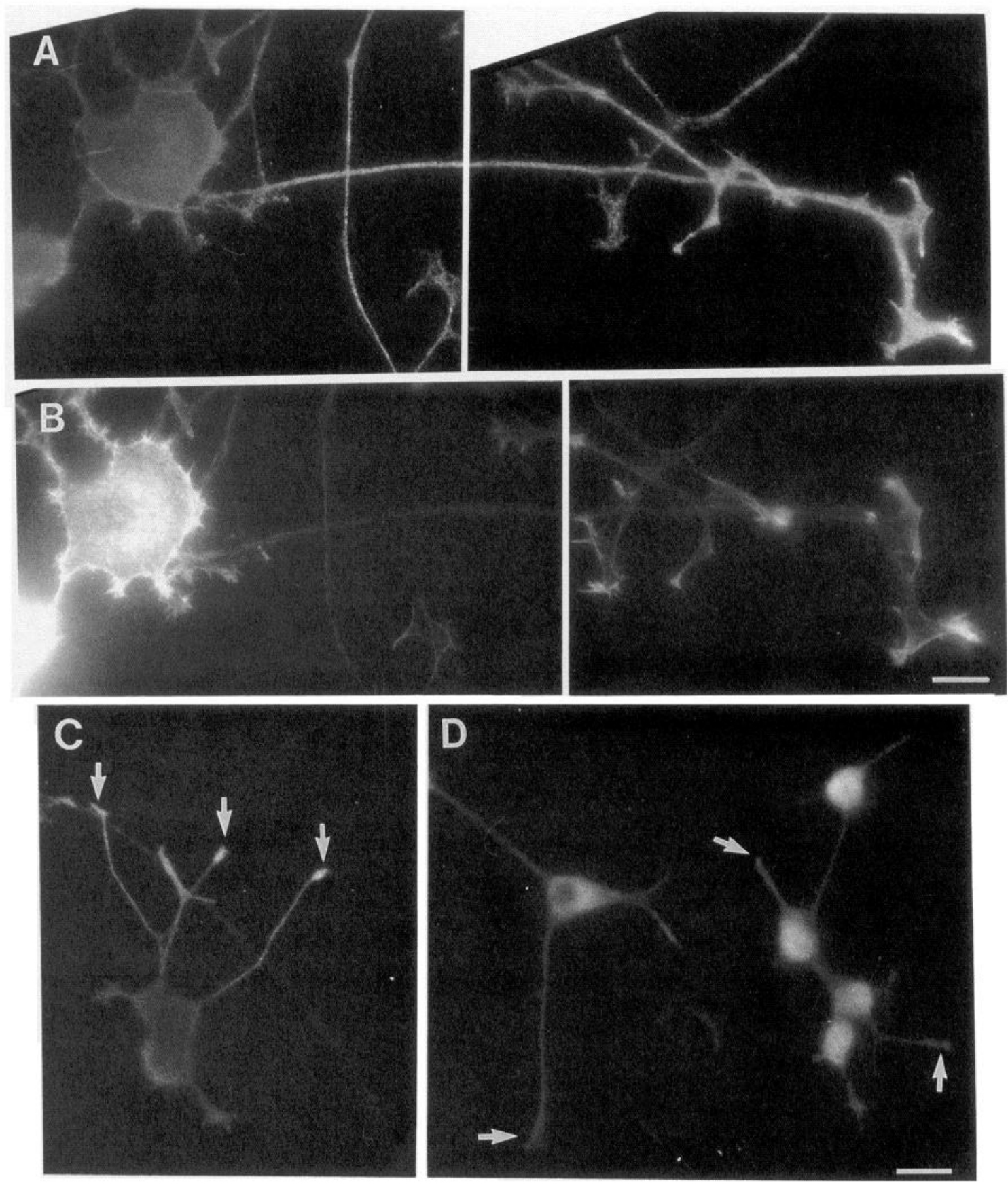

Figure 3. Double label of PC-12 cells with MAb 2E4 and either phalloidin or an anti-actin antibody. $A$ and $B$, MAb 2E4 stains the neurite and growth cone $(A)$ while phalloidin stains the cell body and tufts of actin filaments in the growth cone. $C$ and $D$, At low magnification MAb 2E4 again can be seen to stain neurites and growth cone (arrows, $C$ ) while an anti-actin monoclonal antibody of the same isotype as MAb 2E4 (D) stains the cell body and the growth cones (arrows) and only very weakly the neurite. At longer exposures, which would overexpose the growth cones, MAb 2E4 staining can also be detected in the cell body. Scale bars: $A$ and $B, 10 \mu \mathrm{m} ; C$ and $D, 20 \mu \mathrm{m}$.

Perinuclear staining by MAb $2 E 4$ does not colocalize with the Golgi apparatus, but rather with the microtubule organizing center

Since the Golgi apparatus is a prominent perinuclear structure, it originally seemed likely that the antigen was concentrated in the Golgi, explaining its perinuclear staining. However, double labeling with three different Golgi-specific probes failed to reveal colocalization between MAb 2E4 staining and the Golgi. Both WGA (Fig. 4A), which recognizes the Golgi network (Goslin et al., 1990), and a polyclonal antibody against a $135 \mathrm{kDa}$ Golgiassociated glycoprotein from rat liver, which recognizes the transGolgi compartment (Fig. 4C) (Burke et al., 1982), identified an aggregate of membrane systems to one side of the nucleus in undifferentiated cells. By double-label immunofluorescence, the staining by these two probes overlapped, although the WGA staining was less precisely localized, and staining of the nuclear envelope and plasma membrane contributed to a high background, not surprising for this less specific probe. Double label with WGA (Fig. 4A) and MAb 2E4 (Fig. $4 B$, same cells as $A$ ) 

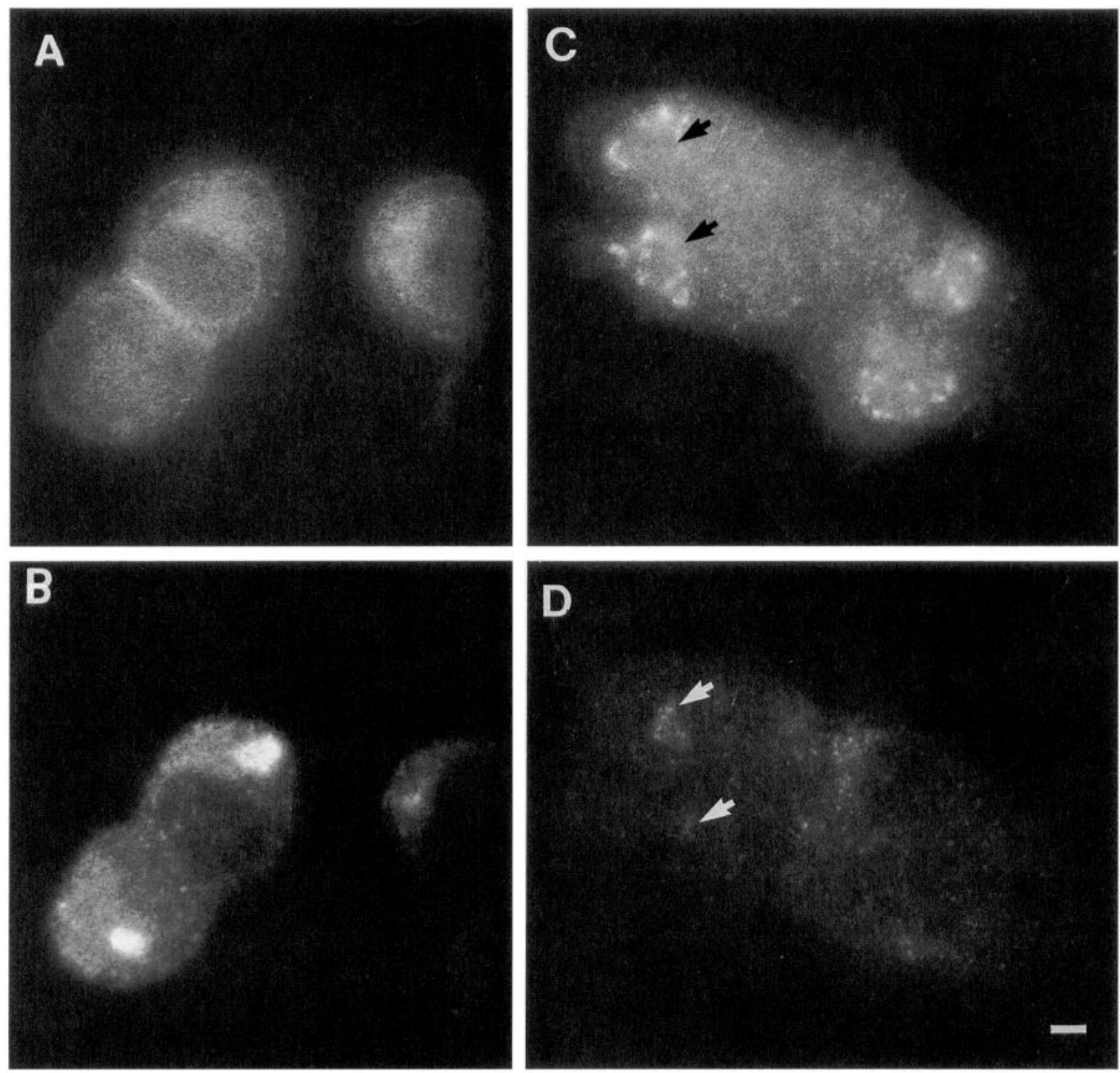

Figure 4. Perinuclear staining by MAb 2E4 is in the region of the Golgi apparatus but not coincident with it. $A$ and $C$, Two sets of cells ( $A$ and $B, C$ and $D)$ double labeled with MAb 2 E4 $(B$ and $D)$ and for Golgi with either WGA $(A)$ or anti-Golgi antibody $(C)$. $A$ and $B$ show the same cells photographed with different filter sets, and $C$ and $D$ show the same cells. Note that while the MAb $2 \mathrm{E} 4$ staining is in the same general region as the Golgi, it occupies an area not stained by either Golgi probe, which appears darker in the micrographs of the cells stained with anti-Golgi antibody (arrows in $C$ denote MAb 2E4-stained/Golgi-negative structure; arrows in $D$ point to the same region that is stained by the 2E4 antibody). Scale bar, $5 \mu \mathrm{m}$.

or anti-Golgi polyclonal antibodies (Fig. 4C) and MAb 2E4 (Fig. $4 D$, same cells as $C$ ) showed that the MAb 2E4-stained structure was often located in the region of the Golgi membranes but was a separate area not stained by either Golgi probe. NBD-ceramide, which is a lipid dye that becomes trapped and concentrated in the Golgi apparatus of living cells (Pagano et al., 1989), confirmed that these cells have a large Golgi that occupies a large portion of the cytoplasm to one side of the nucleus.

Since the centrosome, including its microtubule organizing center (MTOC), is usually found within the Golgi apparatus but excludes Golgi cisternae from the electron-dense cytoplasm that surrounds it (Brinkley, 1985), it appeared likely that the perinuclear localization of the $43 \mathrm{kDa}$ antigen would be in the centrosomal region. The MTOC of these cells is difficult to observe by immunofluorescence with anti-tubulin antibodies if fixation preserves microtubules. This is because the cells are round and contain a large number of microtubules. When these cells were treated with $10 \mu \mathrm{g} / \mathrm{ml}$ colcemid and then fixed with paraformaldehyde, the position of the MTOC could be detected with anti-tubulin antibodies (Lefcourt and Bentley, 1989). Double label of PC-12 cells with MAb 2E4 (Fig. $5 A$ ) and anti-tubulin antibodies (Fig. $5 B$ ) after this treatment demonstrated a superimposition of this tubulin-containing region with the perinuclear structure stained with MAb 2E4 (Fig. 5C, double exposure of $A$ and $B$ ). The MAb 2E4 staining in some cells appears to coincide precisely with the anti-tubulin staining, while in other cells the two structures are not quite in exactly the same focal plane. In the fluorescein channel of anti-tubulin staining, there is a high level of background fluorescence from the depolymerized tubulin. This sometimes obscures the signal from the MTOC, which might prevent detection of overlap between the two channels.

These results, taken together with the Golgi-MAb 2E4 double staining, suggest that the MAb 2E4 antigen is in the region of 

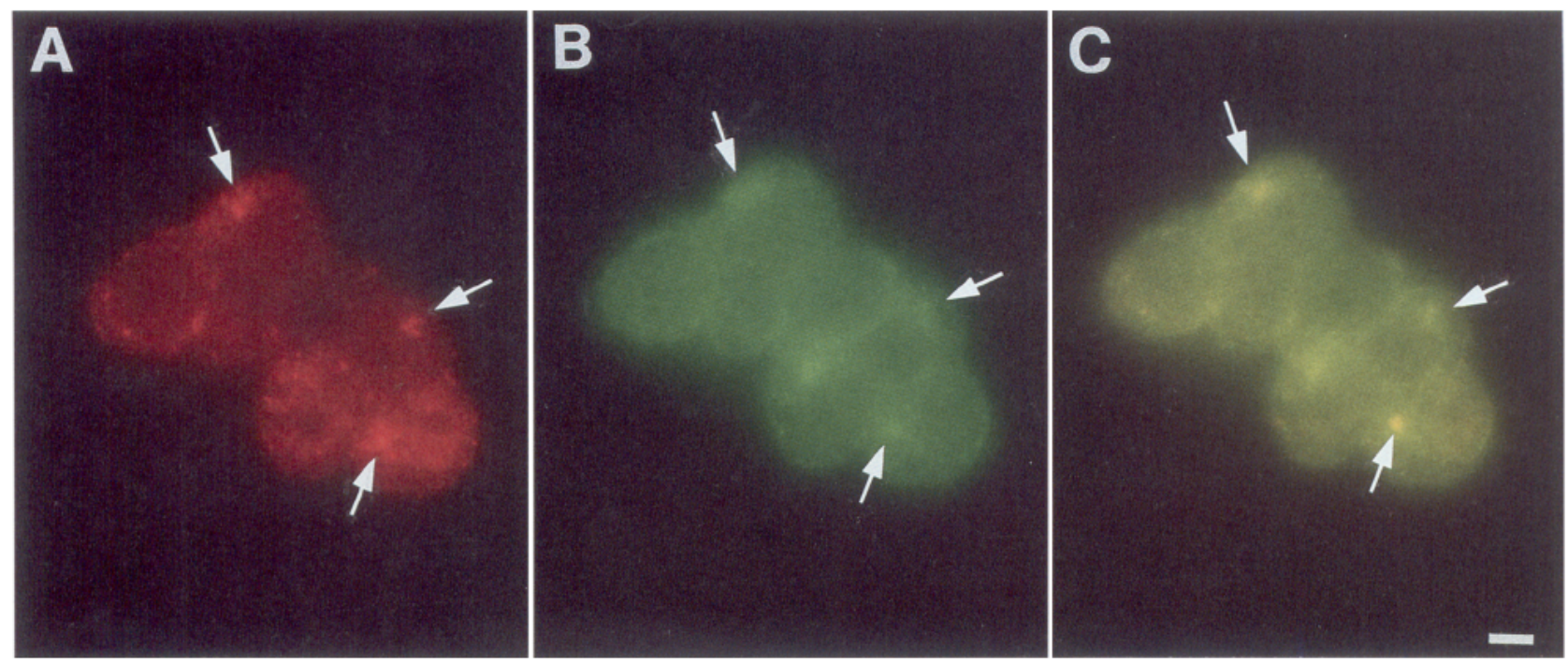

Figure 5. The perinuclear region stained by MAb 2E4 also stains with anti-tubulin antibodies after depolymerization of the microtubules. Double label with MAb 2E4 $(A)$ and anti-tubulin antibodies $(B)$ reveals that the two regions of brightest stain (some indicated by arrows) are often in the same region in double-exposed micrographs $(C)$. Scale bar, $10 \mu \mathrm{m}$.

the centrosome but not within it. In some cells, a darker area inside the bright ball of staining by MAb $2 \mathrm{E} 4$ could be seen at high magnification, perhaps indicating the site of the centrosome.

The loss of centrosomal staining appeared to correlate with the length of the neurite outgrowth. To quantitate this, I measured the length of the longest neurite in 103 cells from three different cultures of cells that were stimulated for $7 \mathrm{~d}$ with NGF. In such cultures, a wide range of differentiation is observed, with some cells remaining round and other cells extending neurites for over $100 \mu \mathrm{m}$. Cells were selected at random and scored for presence or absence of centrosomal staining by MAb 2E4. A histogram displaying these results is shown in Figure 6. While MAb 2E4 stained $90 \%$ of cells with neurites less than $20 \mu \mathrm{m}$ (one cell body diameter) long, only rarely was the centrosomal region stained in cells with neurites longer than $60 \mu \mathrm{m}$ (three cell body diameters).

\section{$P C-12$ cells contain a $43 \mathrm{kDa}$ protein recognized by $M A b 2 E 4$ and similar in behavior to the MAb $2 E 4$ antigen identified in the leading edge of chick embryo fibroblasts}

Because the original antigen was a human blood platelet protein, it seemed important to confirm that the antigen recognized in this rat neuronal cell line was not a non-specifically cross-reactive protein. To do this, I compared the biochemical characteristics of the antigen from other tissues with that of the antigen present in PC-12 cells. In addition to its unique staining pattern, the MAb 2E4 antigen has three other biochemical characteristics: it is detected in Western blots as a $43 \mathrm{kDa}$ species, it elutes from filamentous actin affinity columns with ATP, and the antigen-antibody complex associates with the barbed end of actin filaments (Bearer, unpublished observations). In Western blots of homogenates of undifferentiated PC-12 cells (Fig. $7 A$, lane 2 ), the antibody also recognized a $43 \mathrm{kDa}$ band, and faintly a smaller molecular weight species.

The PC-12 cell $43 \mathrm{kDa}$ antigen was partially extracted with Mg-ATP from detergent-insoluble cytoskeletons of undifferentiated PC-12 cells (Fig. 7B,C, Coomassie-stained gel and cor- responding Western blot). By Western blot, the low molecular weight protein present in the homogenate is soluble after detergent lysis (Fig. $7 \mathrm{~B}$, gel, and Fig. $7 \mathrm{C}$, blot, lanes labeled $\mathrm{S}$ ), while most of the $43 \mathrm{kDa}$ antigen remains in the pellet (Fig. $7 B, C$, lanes labeled $\mathrm{P}$ ). The antigen is not extracted by subsequent washes in a buffer containing EGTA (Fig. 7B, $C$, lanes labeled W), even though staining by Coomassie blue reveals that there is at least as much protein in the $43 \mathrm{kDa}$ band. This band probably represents actin. Approximately one-third of the antigen was subsequently extracted from the pellet with Mg-ATP (Fig. 7B,C; lanes AS are supernatant; lanes AP are pellets after Mg-ATP extraction). By Coomassie blue staining, Mg-ATP extracts a number of other proteins from these insoluble cytoskeletons as well, some of which may also bind actin [indicated by dots beside the ATP supernatant (AS) lane in the gel, Fig. 7B]. Note that the lower molecular weight species recognized by the antibody in the homogenate of whole cells are completely soluble after detergent lysis (Fig. $7 C$, lane $\mathrm{S}$ ). Centrosomes are difficult to extract and therefore would not be expected to be solubilized under these conditions but rather to be retained in the pellet (Mitchison and Kirschner, 1986).

Another feature of the antigen extracted from fibroblasts was that it associated with one end of F-actin filaments as visualized directly in an in vitro assay of actin filament binding (Bearer, 1991). In this assay (Fig. $8 A-C$ ), nitrocellulose-coated coverslips are first treated with the monoclonal antibody in a flow chamber. After the coverslip is washed and blocked with BSA, it is incubated with the Mg-ATP extract enriched in the $43 \mathrm{kDa}$ antigen. This attaches the antigen to the nitrocellulose via the antibody. After further washes in blocking buffer, purified actin filaments labeled with rhodamine-phalloidin are perfused into the chamber and allowed to adhere for $5 \mathrm{~min}$, and then the nonadherent filaments are washed out with blocking buffer containing oxygen radical scavengers. The rhodamine-phalloidin permits visualization of the actin filaments by fluorescence microscopy - actin filaments are too small to be detected by light microscopy. Thus, the behavior of the filaments can be observed, including the manner by which they are attached to the 


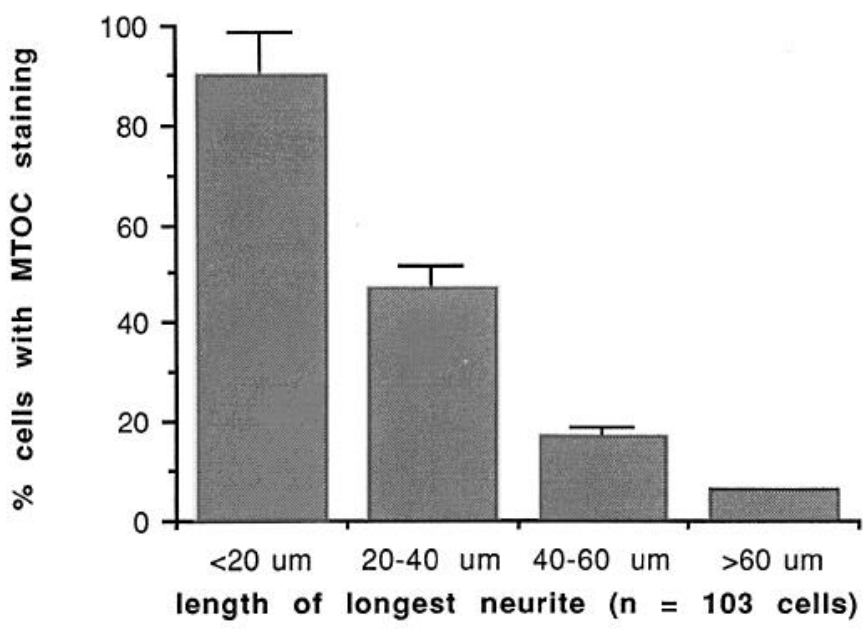

Figure 6. The presence of perinuclear staining is directly proportional to the length of the longest neurite. PC-12 cells stimulated with NGF every second day for $7 \mathrm{~d}$ were fixed and stained with MAb 2E4. Cells were selected at random and placed into categories according to the length of the longest neurite measured. Cells were then scored for the presence or absence of MAb 2E4 staining of the centrosomal region. Approximately the same number of cells in each category were counted. The results were normalized by being presented as a percentage of the total. Error bars reflect the calculated SD.

protein coating the coverslip. Proteins that bind filaments along their length thus produce images of long filaments (Kron and Spudich, 1986), while those that bind the ends produce dots because the unattached length of the filament is very flexible and undergoes rapid movements in solution such that it does not remain in any one place long enough to expose the film. Thus, only the attached end of the filament remains in place long enough to expose the film, which requires a $20 \mathrm{sec}$ exposure. End-binding activity cannot be detected in extracts that also contain side-binding proteins because in this case the filaments stick by both their sides and their ends and dots are not observed.

The ATP extract contains proteins other than the MAb 2E4 antigen by Coomassie-stained gel (Fig. $7 B$, lane AS). When this extract is applied directly to the coverslip, actin filaments stick to it all along their length (Fig. 8A), demonstrating that sidebinding proteins are present in the extract. This is the sort of binding that has been previously reported in this assay for myosin II (Kron and Spudich, 1986), and since this extract is made

Figure 7. MAb 2E4 recognizes a $43 \mathrm{kDa}$ band in undifferentiated PC12 cells. A, A $60 \mathrm{~mm}$ culture dish of undifferentiated PC-12 cells was washed three times in serum-free media at $37^{\circ} \mathrm{C}$ and then solubilized directly in $0.5 \mathrm{ml}$ of boiling gel sample buffer. A $10 \mu \mathrm{l}$ aliquot was electrophoresed in a $10 \%$ SDS polyacrylamide gel and either stained with Coomassie blue (lane 1) or transferred to nitrocellulose and stained for kaptin with MAb 2E4 (lane 2). Note the prominent $43 \mathrm{kDa}$ band, and a faint band of lower molecular weight. $B$ and $C$, ATP extraction of undifferentiated PC-12 cells. Cells were lysed in detergent, and the pellet was washed three times and then extracted with $\mathrm{Mg}$-ATP. Equal volumes were separated by SDS electrophoresis and either stained with Coomassie $(B)$ or transferred and blotted with MAb 2E4 $(C)$. Lane $S$, lysis supernatant; lane $P$, lysis pellet; lane $W$, supernatant from the second wash; lane AS, ATP supernatant (ATP extract); lane AP, nonextracted pellet. Note the extracted bands (dotted) that are found in the lysis pellet, extracted by ATP and thus missing or decreased in the residual pellet. Molecular weight markers are indicated to the left.
A

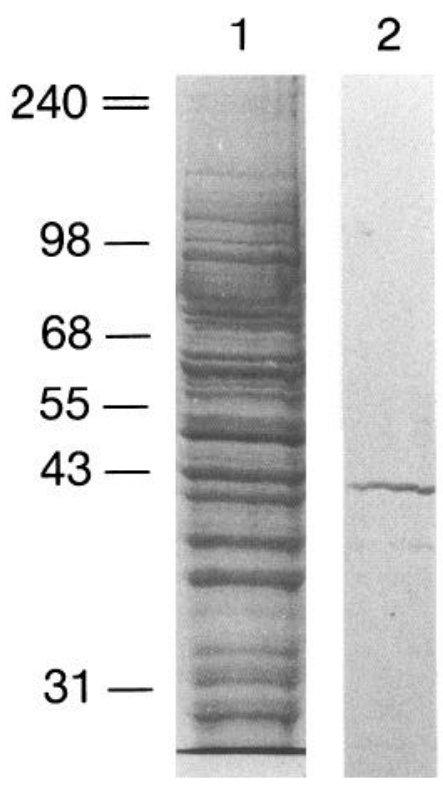

B

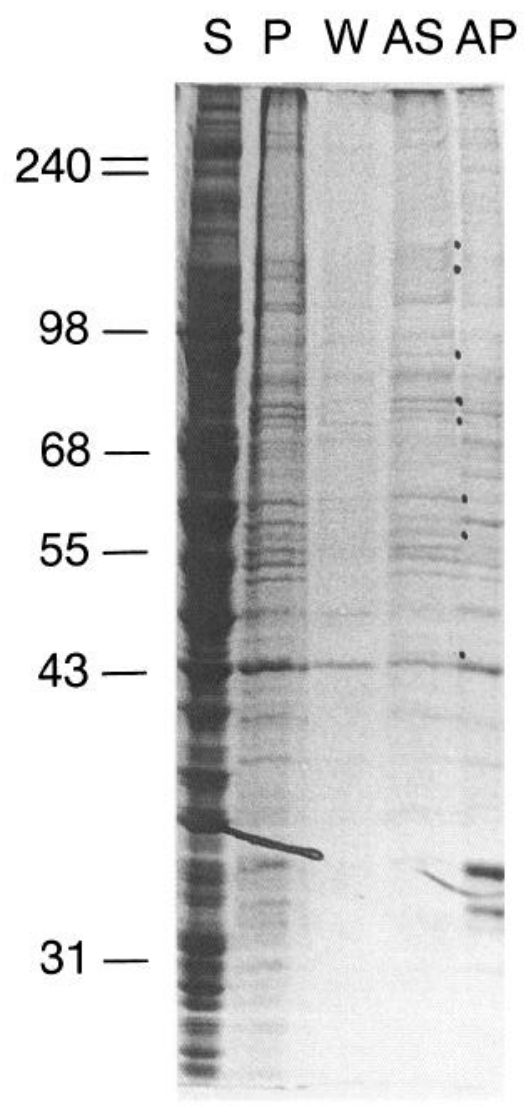

C

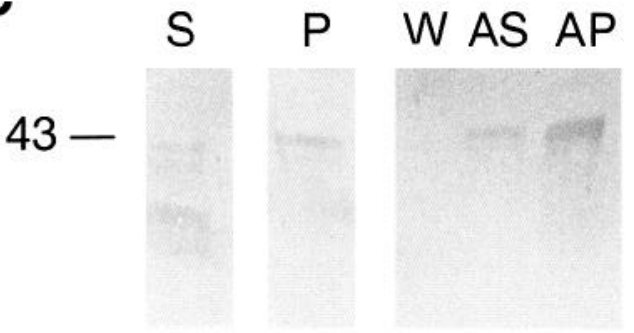



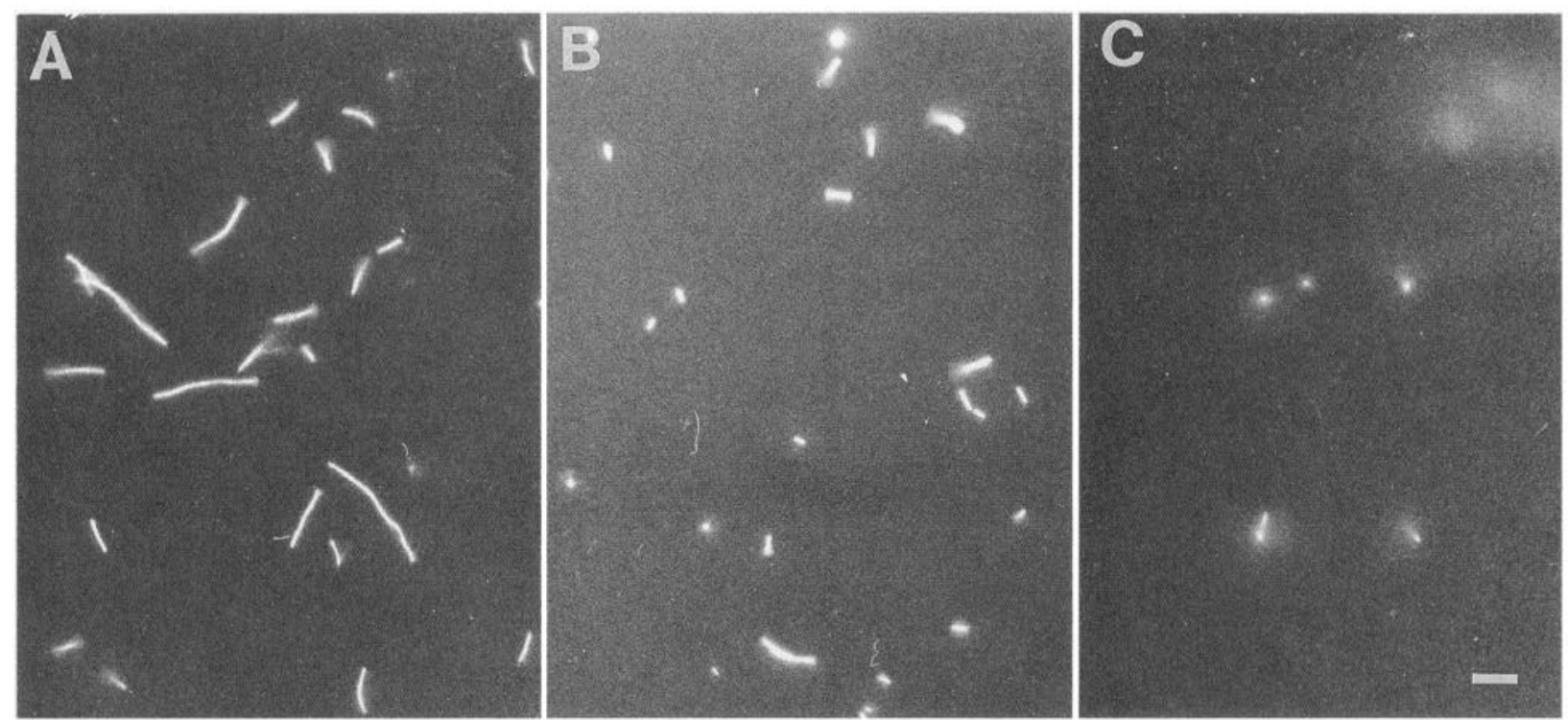

Figure 8. Purified actin filaments stick by one end to nitrocellulose-coated coverslips saturated with MAb 2E4-antigen complexes. A, Actin filaments stick along their lengths to a coverslip coated directly with the ATP extract of undifferentiated PC-12 cells. B, Most actin filaments stick only by one end when the coverslip is first coated with the MAb 2E4 antibody, blocked with albumen, and then allowed to immunabsorb its antigen from the ATP extract from chick embryo fibroblasts. $C$. Attachment of actin filaments by one end is also observed on coverslips treated as in $B$ but with an ATP extract from undifferentiated PC-12 cells. Approximately one-fifth of the total high-power field is shown in each micrograph. Scale bar, $2 \mu \mathrm{m}$.

under conditions that extract the myosins, this side-binding is likely to be in part due to the presence of a myosin in the extract. However, when the coverslips are coated with MAb 2E4 antibody, blocked, treated with the ATP extract from either chick embryo fibroblasts (Fig. $8 \mathrm{~B}$ ) or PC-12 cells (Fig. $8 \mathrm{C}$ ), and washed again, the filaments adhered only by one end, appearing as dots in the micrograph. Antibody alone did not bind filaments, and coverslips incubated in blocking buffer without antibody followed by extract did not retain filaments. There were fewer filaments bound per volume of extract from PC-12 cells than from chick embryo fibroblasts (Table 1). The side-binding proteins present in the ATP extract are apparently not recognized by the antibody, since less than $10 \%$ of the filaments bound to coverslips coated with the antibody-antigen complex are stuck sideways to the coverslip.

This activity can be compared to that of gelsolin, which binds the sides of actin filaments (Bryan, 1988; Yin et al., 1988; Bearer, 1991) and severs them in the presence of calcium, remaining attached to the barbed end after severing (Janmey et al., 1985; Bearer, 1991). Each of these activities of gelsolin have been directly observed with this assay (Bearer, 1991). Monomeric actin would be expected to associate with filaments in the opposite way as the MAb 2E4 antigen-binding filaments more avidly in the presence of ATP rather than dissociating. Since the coverslips are washed after the antibody-antigen complex is formed on them, the buffer conditions of the actin filament preparation (which does not contain ATP) rather than those of the extract are operative when the filaments attach.

\section{The $M A b 2 E 4$ antigen is not an integral centrosomal component}

In order to be sure that the $43 \mathrm{kDa}$ antigen recognized in blots was responsible for the centrosome-associated staining pattern, I extracted cells grown on coverslips under the same conditions used to prepare the gels and blots in Figure 7, but fixed them for immunofluorescence instead of preparing them for biochemical analysis. The centrosomal staining was not removed by the lysis buffer (Fig. 9A) that had removed all of the lower molecular weight species by Western blot (Fig. $7 C$, lane S). However, treatment with lysis buffer did remove much of the diffuse cytoplasmic staining.

The centrosome participates in the elaboration of the mitotic

Table 1. Quantitation of actin filament binding to coverslips coated with antibody-antigen complexes

\begin{tabular}{lllll} 
& BSA + extract & Antibody alone & $\begin{array}{l}\text { Extract } \\
\text { alone }\end{array}$ & $\begin{array}{l}\text { Antibody }+ \\
\text { extract }\end{array}$ \\
\hline PC-12 cells & $0.1 \pm 0.3(10)$ & $0.1 \pm 0.3(10)$ & $24 \pm 4(5)$ & $12.6 \pm 4(5)$ \\
Chick embryo fibroblasts & $0.1 \pm 0.3(10)$ & $0.1 \pm 0.3(10)$ & $46 \pm 6(10)$ & $24.5 \pm 5(20)$ \\
\hline
\end{tabular}

Coverslips were prepared as described in Materials and Methods. The different conditions of preparation are given in the column headings. The numbers reported are the average number of filaments per high-power field (100 $\times$ objective). To obtain this average, the number of actin filaments per each (5-20) randomly selected high-power (100 $\times$ objective) field was counted, and the total number divided by the number of fields counted. SD $( \pm)$ were calculated according to the formula. In control columns ("BSA + extract" and "Antibody + extract," only one filament per 10 high-power fields was observed. This low number caused the SD to come out higher than the mean. The number of high-power fields is given in parentheses. 

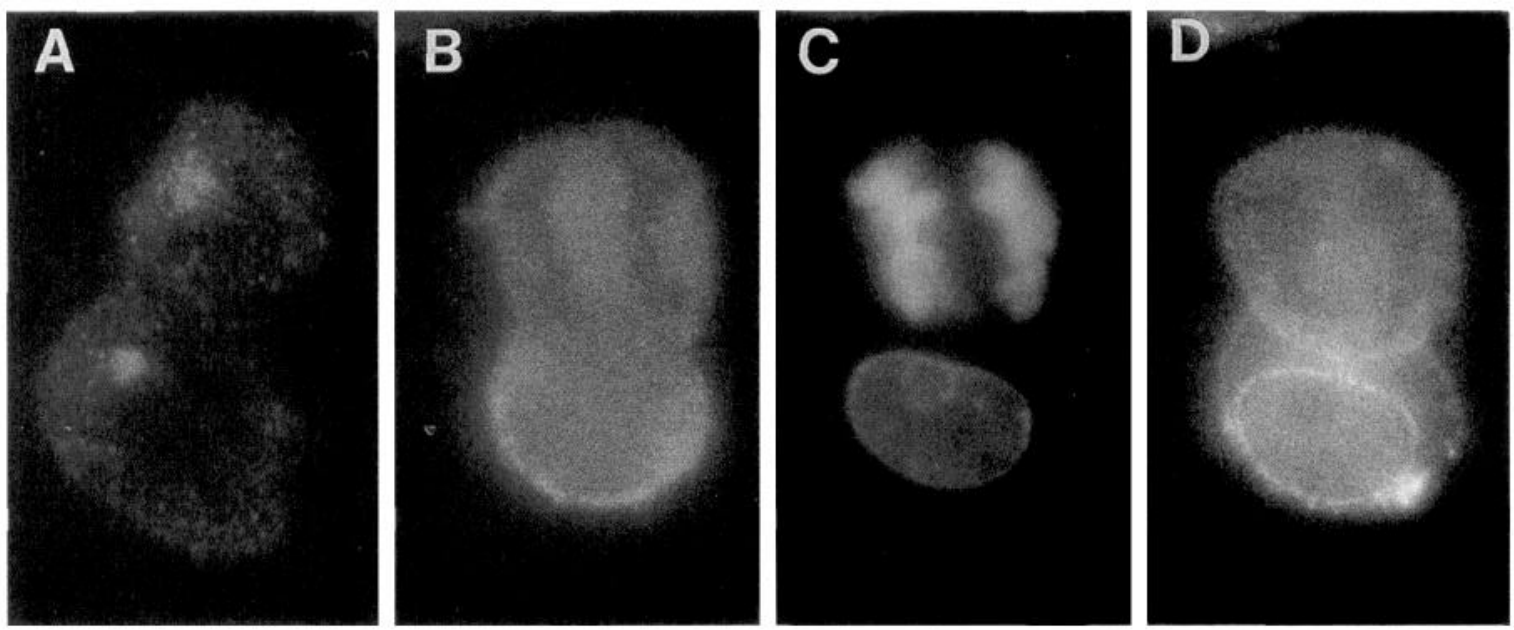

Figure 9. The $43 \mathrm{kDa}$ antigen is not an integral centrosomal protein. $A$, PC-12 cells permeabilized with detergent first and then fixed and stained with MAb $2 \mathrm{E} 4$ still display the perinuclear antigen. $B-D$, Two unstimulated $\mathrm{PC}-12$ cells, one of which is undergoing mitosis, triple labeled with MAb 2E4 $(B)$, Dapi $(C)$, and WGA $(D)$. During mitosis, seen in the upper cell, no localized staining by MAb 2E4 is detected $(B)$. The perinuclear staining was present in the lower cell, which is in interphase, but is not seen in the micrograph because it was out of the focal plane of the dividing chromosomes. The chromosomes are observed to be separating in anaphase $(C)$, and the Golgi has also dispersed $(D)$.

spindle, while cytoplasmic microtubules depolymerize and the Golgi disperses (Ho et al., 1989). It seemed likely that, if the 2E4 antigen were an intrinsic centrosomal protein, it would remain associated with the spindle pole during mitosis, but if it were localized in the centrosomal region for trafficking reasons, it would become diffuse during mitosis. Undifferentiated PC -12 cells had a diffuse staining by MAb $2 \mathrm{E} 4$ during mitosis with no localization to the spindle poles (Fig. 9B), although the chromosomes, stained with Hoechst, could be seen in this particular cell to be in the process of separating (Fig. 9C). WGA also displayed diffuse staining in this mitotic cell consistent with the dispersal of the Golgi apparatus (Fig. 9D).

While MAb 2E4 detected a $43 \mathrm{kDa}$ band in Western blots of isolated neonatal rat growth cones (Fig. 10, lanes 1 and 3), it did not recognize any bands in "purified" centrosomes with intact microtubule nucleating activity from N115 cells (Fig. 10, lanes 2 and 4). These cells also displayed a perinuclear staining pattern with MAb 2E4. It should be noted that while the Coomassie-stained gel of the growth cones has a prominent $43 \mathrm{kDa}$ band (Fig. 10, lane 1), there is only a faint $43 \mathrm{kDa}$ band in the gel of the centrosome preparation (Fig. 10, lane 2). Ten times as much protein from the centrosome preparation was loaded onto the gel used for the transfer blot than that used for the gel to ensure that enough protein was present for a band to be detected by MAb 2E4 if the protein were one of the more major centrosomal proteins. Gap-43 migrates at $50 \mathrm{kDa}$ in these gels and can be seen as the most prominent band in lane 1 . This has been confirmed by Western blot (not shown) and is similar to its reported behavior (Skene and Willard, 1981; Oestreicher and Gispen, 1986; Skene and Virag, 1989).

\section{Discussion}

The object of this study was to investigate the distribution of the actin-associated antigen recognized by the monoclonal antibody MAb 2 E4 in PC-12 cells before and after neurite outgrowth stimulated by NGF. In undifferentiated cells, the MAb

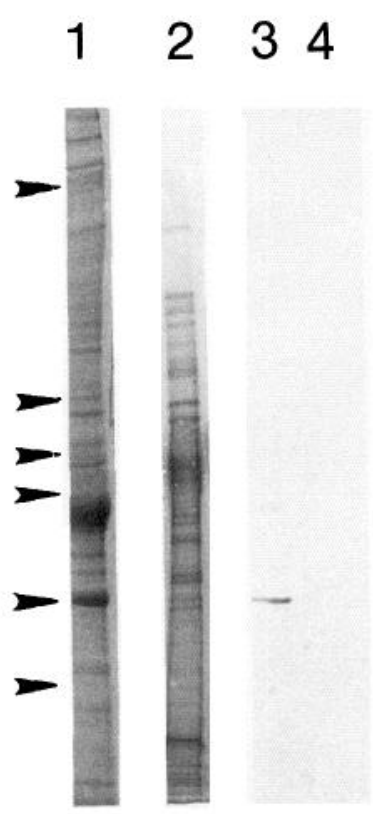

Figure 10. The $43 \mathrm{kDa}$ antigen is present in isolated growth cones but not in isolated centrosomes. Polyacrylamide gel [lane 1 (stained with Coomassie blue) and lane 2 (stained by the silver stain method)] and corresponding transfer blot stained with MAb 2E4 (lanes 3 and 4) of isolated neonatal rat brain growth cones (lanes 1 and 3 ), and isolated centrosomes (lanes 2 and 4). The same amount of protein was loaded onto both growth cone lanes, but 10 times more protein of the centrosomal preparation was loaded onto the lane that was transferred for blotting. Note that the $43 \mathrm{kDa}$ band is very prominent relative to the other bands in the growth cones (lane 1) and barely visible in the centrosomes (lane 2). It is not surprising that the $43 \mathrm{kDa}$ MAb 2E4 antigen is detected only in the growth cone (lane 3). The smaller molecular weight species seen in blots of whole-cell homogenates are not seen in either of these preparations. Molecular weight standards indicated by arrowheads to the left: $220,98,68,55,43$. 
2E4 antigen was present and found as a concentrated ball adjacent to the nucleus that corresponded to the centrosomal region. It was not present in the Golgi apparatus by double-label immunofluorescence. After stimulation with NGF, the cells extended long branching neurites tipped by small growth cones. After such stimulation, MAb 2E4 stained predominantly the neurite and growth cone.

\section{Localization to the growth cone of an actin-associated protein}

It is not surprising that an actin-associated antigen found in the leading edge of a migrating cell should also be present in the growth cone of a neuronal cell since these two processes appear to have very similar properties. The MAb $2 \mathrm{E} 4$ antigen is markedly enriched in the growth cone compared to the cell body. It could be that this differential distribution is an artifact of permeabilization of the cells, since the MAb 2E4 antigen is an IgM, an isotype that is extremely large. However, this is unlikely because the anti-actin antibody, which is also an IgM, stains the cell bodies more brightly than the neurites and growth cones.

The presence of the MAb 2E4 antigen in the growth cone and in the leading edge of migrating fibroblasts suggests that it is involved in actin filament reorganizations occurring in these locations. Like gelsolin, the antigen is not uniquely associated with filaments (Cooper et al., 1988). Since in vitro the antibodyantigen complex associates with the barbed end of actin filaments in an ATP-sensitive manner, it is likely to be a "capping" protein, that is, a protein that guards the fast-growing end of the actin filament, permitting monomer addition and subsequent barbed end elongation of the filament only under certain conditions, or perhaps promoting pointed end elongation. There is a critical role for such a protein in the growth cone. Since actin filaments are essential for the guidance of elongating neurites (Marsh and Letourneau, 1984) and the proper distribution of membrane surface antigens (Forscher and Smith, 1990; Sheetz et al., 1990), regulation of polymerization by a barbed-endbinding protein could result in influencing these functions as well. Furthermore, it appears that actin filaments polymerize off the anterior edge of the membrane of the lamellipodia of the growth cone (Forscher and Smith, 1988). Once filaments are formed, they could then serve as tracks for the movements of membrane receptors, such as the forward transport of the $2 \mathrm{~A} 1$ antigen (Sheetz et al., 1990) or the rearward movement of surface particles (Forscher and Smith, 1990). Such an organized parallel array of filaments has been observed in human blood platelets (Bearer, 1990). This single layer of filaments lies just beneath the membrane surface and is visible in rapidly frozen, fractured, and deep-etched cells.

\section{Localization in the undifferentiated cell}

In undifferentiated PC-12 cells, MAb 2E4 stains a perinuclear structure that colocalizes with the MTOC. Since the antibody blots to two protein bands in Western blots of whole-cell homogenates, the perinuclear staining could have been due to an enrichment of the other lower molecular weight species in that location. However, this lower molecular weight band is solubilized under conditions that do not solubilize the centrosome (Mitchison and Kirschner, 1986). In addition, after such solubilization the immunofluorescent staining of the centrosomal region by $\mathrm{MAb} 2 \mathrm{E} 4$ persists. Thus, it seems most likely that the antigen recognized in the centrosomal region is the $43 \mathrm{kDa}$ species. Neither the $43 \mathrm{kDa}$ nor the lower molecular weight antigen copurifies with the microtubule-nucleating activity of purified centrosomes from N115 cells, suggesting that the MAb 2E4 antigen is not necessary for that functional role of the centrosome. In addition, the antigen is not localized to the centrosome during mitosis. Thesc results, together with the slight offcenter alignment of the microtubule center with MAb 2E4stained perinuclear structure, imply that the antigen is located in the periphery of the centrosome and is not intrinsic to it.

What could be the purpose of an ATP-insoluble pool of protein in the centrosomal region of undifferentiated cells? It may be in the process of being degraded, recycled, or stored for future transport to a site of action. If it is being degraded, it is probably not in the lysosomal system of degradation, since lysosomes are only loosely associated with the centrosomal region (Heuser, 1989) and are more scattered and granular in these cells than is the MAb 2E4-stained perinuclear structure (Johnston et al., 1989). The idea that this insoluble pool is a store of inactive protein either being recycled or stored is attractive, in that one might imagine a nucleator would need to be inactive until it had reached its appropriate position in the cell, which could be a long way from its site of synthesis. Two pieces of evidence support the idea that the centrosome-associated antigen is inactive. First, the $43 \mathrm{kDa}$ antigen is not efficiently solubilized from PC-12 cells with ATP. Since Mg-ATP dissociates this antigen from actin filaments, it is likely that its presence in the centrosomal region is not due to an ATP-sensitive actin filament association. Second, the antibody-antigen complex has less actin filament-binding activity when the antigen is extracted from PC-12 cells than when extracted from fibroblasts. Thus, it may be that some of the antigen that is extracted is not active. Additionally, it is possible that the antigen is activated during extraction by some other protein released during lysis or present in the ATP extract.

Neurite formation probably involves the activation and redistribution of proteins already present in the cell as well as synthesis of new proteins. The fact that MAb $2 E 4$ detects the $43 \mathrm{kDa}$ antigen in PC-12 cells that have not been induced to produce neurites indicates that synthesis of this antigen is unlikely to be the triggering event for neurite outgrowth. Rather, relocation of the antigen appears to be part of the NGF response. In lymphocytes, another actin-associated protein, spectrin, redistributes from the centrosome to the cell membrane upon activation (Black et al., 1988). This redistribution may be analogous to the change in location of the MAb 2E4 antigen from the centrosomal region to the growth cone after NGF stimulation of PC- 12 cells. Since the present study was performed on fixed cells, it is not possible to tell whether the same protein recognized by $\mathrm{MAb} 2 \mathrm{E} 4$ in the centrosome of unstimulated cells is moved from the centrosome to the growth cone or whether newly synthesized protein is transported directly to the growth cone independent of the centrosome. However, it is tempting to hypothesize that the presence of the MAb 2E4 antigen in the centrosomal region of the undifferentiated cell is related to its future transport out the neurite to the growth cone during NGFinduced differentiation. The correlation between the loss of centrosomal staining as the growing neurite elongates supports this notion, as do a number of observations from other systems. One of these is that the centrosome is positioned subjacent to the future site of growth cone emergence in the pioneer neurons of the grasshopper limb bud (Lefcourt and Bentley, 1989), and in PC-12 cells the centrioles often reside on the same face of the nucleus from which the initial neurite arises (Stevens et al., 1988). Because the centrosome is known to be involved in the 
nucleation of microtubules, these observations point toward a role for microtubules in the elaboration of the growth cone. Indeed, one putative actin-associated protein, a neuronal ezrinlike protein, which colocalizes with the anterior actin frill in the growth cone, depends upon an intact microtubule system to become enriched in the growth cone (Goslin et al., 1989). These are not new ideas. It has long been proposed (Hoffman and Lasek, 1975; Lasek and Hoffman, 1976; Lasek et al., 1984; Vallee and Bloom, 1991) that microtubules such as those originating in the centrosome might support the slow transport of cytoskeletal proteins in aggregates called "parcels" out the neurite to the growth cone (Hollenbeck and Bray, 1987). This is the first timc, to my knowledge, that an actin-associated protein found in the growth cone has been observed to be also present in the MTOC prior to neurite outgrowth.

\section{References}

Bearer EL (1990) Platelet membrane-skeleton revealed by quick-freeze deep-etch. Anat Rec 227:1-11.

Bearer EL (1991) Direct observation of actin filament severing by gelsolin, and binding by gCap 39, and CapZ. J Cell Biol 115:16291638.

Black JD, Koury ST, Bankert RB, Repaskey EA (1988) Heterogeneity in lymphocyte spectrin distribution: ultrastructural identification of a new spectrin-rich cytoplasmic structure. J Cell Biol 106:97-109.

Bridgeman PC, Dailey ME (1989) The organization of myosin and actin in rapidly frozen nerve growth cones. J Cell Biol 108:95-109.

Brinkley BR (1985) Microtubule organizing centers. Annu Rev Cell Biol 1:145-172.

Bryan J (1988) Gelsolin has three actin-binding sites. J Cell Biol 106: $1553-1562$.

Burke B, Griffiths G, Reggio H, Louvard D, Warren G (1982) A monocional antibody against a $135-\mathrm{K}$ Golgi membrane protein. EMBO J 1:1621-1628.

Connolly JL, Green SA, Green LA (1984) Comparison of rapid changes in surface morphology and coated pit formation of PC 12 cells in response to nerve growth factor, epidermal growth factor, and dibutyryl cyclic AMP. J Cell Biol 89:457-465.

Cooper JA, Loftus DJ, Frieden C, Bryan J, Elson EL (1988) Localization and mobility of gelsolin in cells. J Cell Biol 106:1229-1240.

Forscher P, Smith SJ (1988) Actions of cytochalasins on the organization of actin filaments and microtubules in a neuronal growth cone. J Cell Biol 107:1505-1516.

Forscher P, Smith SJ (1990) Cytoplasmic actin filaments move particles on the surface of a neuronal growth cone. In: Optical microscopy for biology, pp 459-471. New York: Wiley Liss.

Gordon-Weeks PR (1987) The cytoskeletons of isolated, neuronal growth cones. Neuroscience 21:977-989.

Goslin K, Birgbauer E, Banker G, Solomon F (1989) The role of cytoskeleton in organizing growth cones: a microfilament-associated growth cone component depends upon microtubules for its localization. J Cell Biol 109:1621-1631.

Goslin K, Shreyer DJ, Skene JP, Banker G (1990) Changes in the distribution of Gap-43 during development of neuronal polarity. $J$ Neurosci 10:588-602.

Greene LA, Tischler AS (1976) Establishment of a noradrenergic clonal cell line of rat adrenal pheochromocytoma cells which respond to nerve growth factor. Proc Natl Acad Sci USA 73:2424-2428.

Heuser JE (1989) Changes in lysosomal shape and distribution correlated with changes in cytoplasmic $\mathrm{pH}$. J Cell Biol 108:855-864.

Ho WC, Allan VK, van Meer G, Berger EG, Kreis TE (1989) Reclustering of scattered Golgi elements occurs along microtubules. Eur J Cell Biol 48:250-263.

Hoffman PN, Lasek RJ (1975) The slow component of axonal trans- port: identification of major structural polypeptides and their generality among mammalian neurons. J Cell Biol 66:351-366.

Hollenbeck PJ, Bray D (1987) Rapidly transported organelles containing membrane cytoskeletal components: their relationship to axonal growth. J Cell Biol 105:2827-2835.

Janmey PA, Chaponnier C, Lind SE, Zaner KS, Stossel TP, Yin HL (1985) Interactions of gelsolin and gelsolin : actin complexes with actin. Effects of calcium on actin nucleation, severing and end-blocking. Biochemistry 24:3714-3723.

Johnston PA, Cameron PL, Stukenbrok H, Jahn R, De Camilli P, Sudhof TC (1989) Synaptophysin is targeted to similar microvesicles in CHO and PC 12 cells. EMBO J 8:2863-2872.

Kron SJ, Spudich JA (1986) Fluorescent actin filaments move on myosin fixed to a glass surface. Proc Natl Acad Sci USA 83:62726276.

Kron SJ, Toyoshima T, Uyeda QP, Spudich JA (1991) Assays of actin sliding movement over myosin surfaces. In: Methods in enzymology (Vallee R, ed) 196:399-416. New York: Academic.

Lasek RJ, Hoffman PN (1976) The neuronal cytoskeleton, axonal transport, and axonal growth. In: Cell motility (Goldman R, Pollard T, Rosenbaum J, eds), pp C1021-C1049. Cold Spring Harbor, NY: Cold Spring Harbor Laboratory.

Lasek RJ, Garner JA, Brady ST (1984) Axonal transport of the cytoplasmic matrix. J Cell Biol 99:212s-221s.

Lefcourt F, Bentley D (1989) Organization of cytoskeletal elements and organelles preceding growth cone emergence from an identified neuron in situ. J Cell Biol 108:1737-1749.

Marsh L, Letourneau PC (1984) Growth of neurites without filopodial or lamellipodial activity in the presence of cytochalasin B. J Cell Biol 99:2041-2047.

Mitchison TJ, Kirschner MW (1986) Isolation of mammalian centrosomes. Methods Enzymol 134:261-269.

Oestreicher AB, Gispen WH (1986) Comparison of the immunocytochemical distribution of the phosphoprotein B-50 in the cerebellum and hippocampus of immature and adult rat brain. Brain Res 375 : 267-279.

Okabe S, Hirokawa N (1990) Turnover of fluorescently labeled tubulin and actin in the axon. Nature 343:479-482.

Pagano RE, Sepanski MA, Martin OC (1989) Molecular trapping of a fluorescent ceramide analogue at the Golgi apparatus of fixed cells: interaction with endogenous lipids provides a trans-Golgi marker for both light and electron microscopy. J Cell Biol 109:2067-2079.

Pollard TD, Cooper JA (1986) Actin and actin-binding proteins: a critical review. Annu Rev Biochem 55:987-1035.

Rinnerthaler G, Geiger B, Small JV (1988) Contact formation during fibroblast locomotion: involvement of membrane ruffles and microtubules. J Cell Biol 106:747-760.

Sheetz MP, Baumrind NL, Wayne DB, Pearlman AL (1990) Concentration of membrane antigens by forward transport and trapping in neuronal growth cones. Cell 61:231-241.

Skene JP, Virag I (1989) Post-translational membrane attachment and dynamic fatty acylation of a neuronal growth cone protein, GAP-43. J Cell Biol 108:613-624.

Stevens JK, Trogadis J, Jacobs JR (1988) Developmental control of axial neurite form: a serial electronmicroscopic analysis. In: Intrinsic determinants of neuronal form and function (Lasek RJ and Black MM, eds), pp 115-145. New York: Liss.

Tilney LG, Bonder EM, DeRosier DR (1981) Actin filaments elongate from their membrane-associated ends. J Cell Biol 90:485-494.

Trinkaus JP (1984) Cells into organisms: the forces that shape the embryo, pp 231-237. Englewood Cliffs, NJ: Prentice-Hall.

Vallee RB, Bloom GS (1991) Mechanisms of fast and slow axonal transport. Annu Rev Neurosci 14:59-92.

Wang YL (1985) Exchange of actin at the leading edge of fibroblasts: possible role of treadmilling. J Cell Biol 101:597-602.

Willard M, Skene JHP (1981) Changes in axonally transported proteins during axon regeneration in toad retinal ganglion cells. J Cell Biol 89:86-95.

Yin HL, Iida K, Janmey PA (1988) Identification of a polyophosphoinositide-modulated domain in gelsolin which binds to the sides of actin filaments. J Cell Biol 106:805-812. 